\title{
Core Replacements in a Potent Series of VEGFR-2 Inhibitors and Their Impact on Potency, Solubility, and hERG
}

\author{
Nello Mainolf, ${ }^{*}{ }^{\dagger}, \S$ James Powers, ${ }^{* \dagger}{ }^{\dagger}$ Erik Meredith, ${ }^{\dagger}$ Jason Elliott, $^{\dagger}$ Karl G. Gunderson, ${ }^{\dagger}$ Stephen Poor, $^{\ddagger}$
} Fang Liu, and Karen Anderson ${ }^{\ddagger}$

${ }^{\dagger}$ Global Discovery Chemistry, Novartis Institutes for Biomedical Research, 100 Technology Square, Cambridge, Massachusetts 02139, United States

${ }^{\ddagger}$ Ophthalmology, Novartis Institutes for Biomedical Research, 500 Technology Square, Cambridge, Massachusetts 02139, United States

Supporting Information

ABSTRACT: Anti-VEGF therapy has been a clinically validated treatment of age-related macular degeneration (AMD). We have recently reported the discovery of indole based oral VEGFR-2 inhibitors that provide sustained ocular retention and efficacy in models of wet-AMD. We disclose herein the synthesis and the biological evaluation of a series of novel core replacements as an expansion of the reported indole based VEGFR-2 inhibitor series. Addition of heteroatoms to the existing core and/or rearranging the heteroatoms around the $6-5$ bicyclic ring structure produced a series of compounds that generally retained good on-target potency and an improved solubility profile. The hERG affinity was proven not be dependent on the change in lipophilicity through alteration of the core structure. A serendipitous discovery led to the identification of a

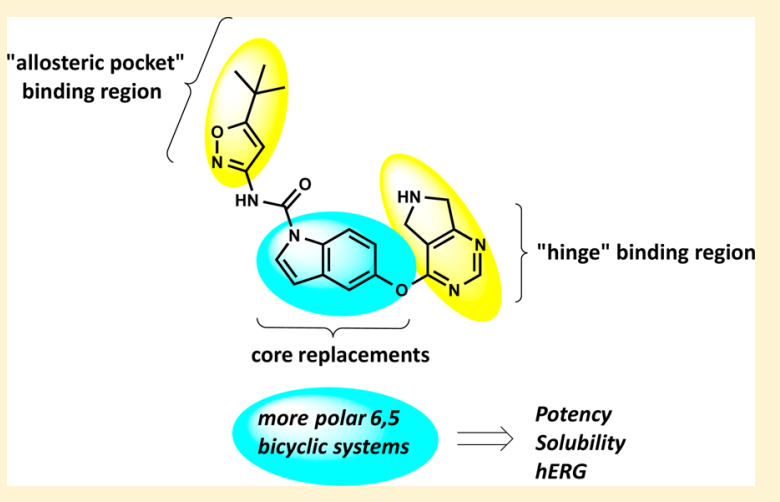
new indole-pyrimidine connectivity: from 5-hydroxy to 6-hydroxyindole with potentially vast implication on the in vitro/in vivo properties of this class of compounds.

KEYWORDS: Vascular endothelial growth factor receptor 2, VEGF, KDR, bicyclic core, scaffold morphing, AMD

$\mathrm{T}$ he current approved therapies for the treatment of wet or neovascular AMD are the anti-VEGF-A antibody ranibizumab, the anti-VEGF-A aptamer pegaptanib, and the anti-VEGF-A trap fusion protein aflibercept. Each of these wetAMD treatments must be delivered by intravitreal injections, and 60 percent of patients do not experience a clinically
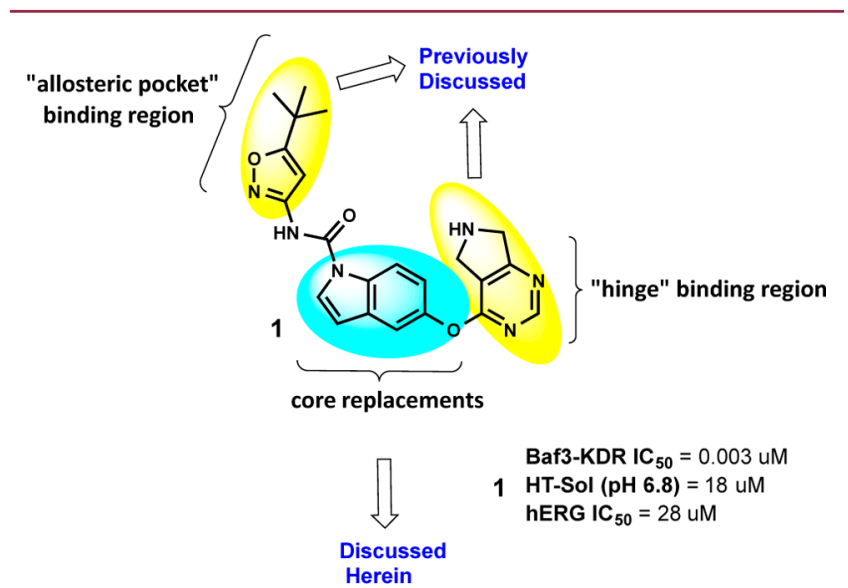

Figure 1. Representative example (1) of previously reported indole pyrimidine scaffold. ${ }^{5}$ significant gain of visual acuity ( $\geq 15$ letters). ${ }^{1}$ Based on this we have envisioned an opportunity for orally available inhibitor of the receptor tyrosine kinase (RTK) VEGFR-2 (KDR, Flt-1) to provide an alternative wet-AMD treatment paradigm. The role of VEGF-A in the regulation of angiogenesis is well established, and although, new vessel growth and maturation are highly complex processes, requiring the sequential activation of a series of receptors by numerous ligands, VEGF-A signaling often represents a critical rate-limiting step. ${ }^{2}$ VEGF-A promotes growth of vascular endothelial cells and is also known to induce vascular leakage. Ocular VEGF-A levels are increased in neovascular diseases of the retina such as neovascular AMD.,

We have recently disclosed the medicinal chemistry efforts around the indole-pyrimidine series of VEGFR-2 inhibitors ${ }^{5}$ where several approaches were taken toward modulation of ontarget potency, solubility, pk, and in vivo efficacy. This was accomplished by focusing on the optimization of the two extremities of the molecules: the urea and the pyrimidine. ${ }^{5}$ Herein, we focus on the modification/replacement of the

Received: January 19, 2016

Accepted: March 16, 2016

Published: March 16, 2016 
Scheme 1. Retrosynthetic Scheme to Access Compounds $1^{5, a}$
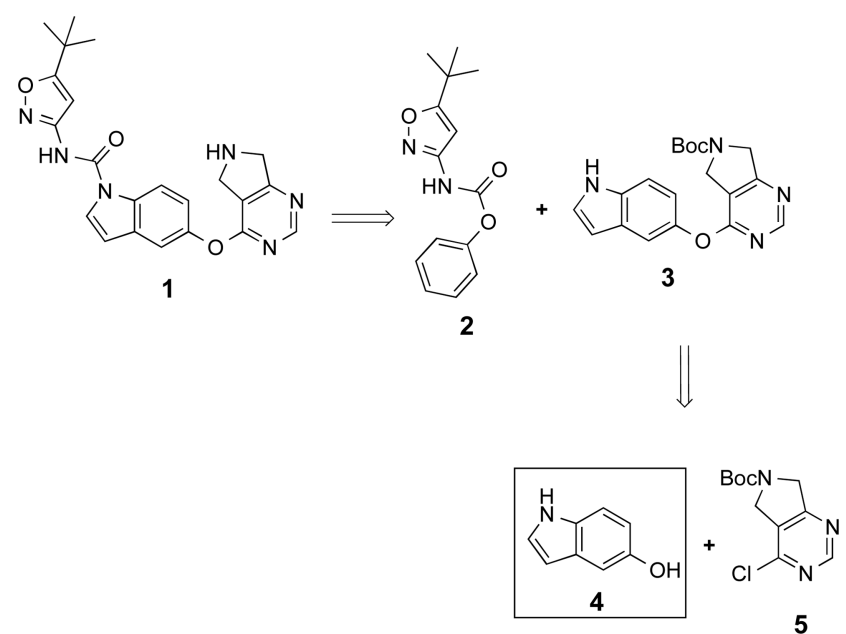

${ }^{a}$ Replacements of hydroxy indole 4 will be discussed herein.

Scheme 2. Synthesis of Imidazopyridine 8 and Its Use in the Synthesis of VEGFR-2 Inhibitor $13^{a}$<smiles></smiles><smiles>CCOC(=O)c1cnc2cc(Oc3ncnc4c3CN(C(=O)O)C4)ccn12</smiles>

10

11

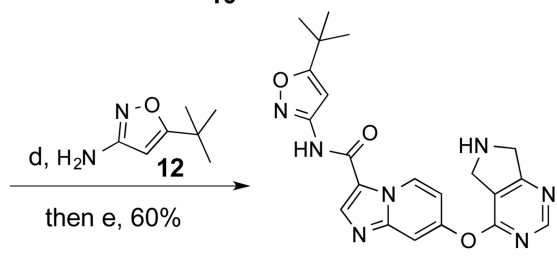

13

${ }^{a}$ Reagents and conditions: (a) 7 ( 3 equiv), EtOH, $72{ }^{\circ} \mathrm{C}, 3 \mathrm{~h}$; (b) 9 (1.5 equiv), PyBOP (1.3 equiv), DBU ( 4 equiv), $\mathrm{CH}_{3} \mathrm{CN}, 60^{\circ} \mathrm{C}, 3 \mathrm{~h}$; (c) $\mathrm{LiOH}$ (40 equiv), $\mathrm{THF} / \mathrm{H}_{2} \mathrm{O}(1: 1)$, rt; (d) oxalyl chloride (1.5 equiv), DMF (cat.), DCM, $0{ }^{\circ} \mathrm{C}$ then 12 (8 equiv), pyridine (20 equiv), rt, overnight; (e) DCM/TFA (1:1), $1 \mathrm{~h}$.

indole core and discuss how those changes modulate in vitro potency, solubility, and hERG activity (Figure 1).

Introducing heteroatoms in flat aromatic rings is often used to reduce lipophilicity and hence improve aqueous solubility, reduce hERG activity, ${ }^{6-16}$ and generally enhance the overall developability profile of drug candidates. ${ }^{17,18}$

We decided to investigate how, the introduction of heteroatoms (especially nitrogens) in the $6-5$ bicyclic aromatic system would impact its potency against VEGFR-2, aqueous solubility at $\mathrm{pH} 6.8$, and hERG channel activity. In order to facilitate interpretation of the data the pyrimidine and the urea moieties were mostly kept constant in the selection of compounds presented herein (Figure 1).

The synthetic strategy to access most of the compounds in this class of VEGFR-2 inhibitors entails a condensation
Scheme 3. Synthesis of Pyrrolopyridine 18 and Its Use in the Synthesis of VEGFR-2 Inhibitor $20^{a}$

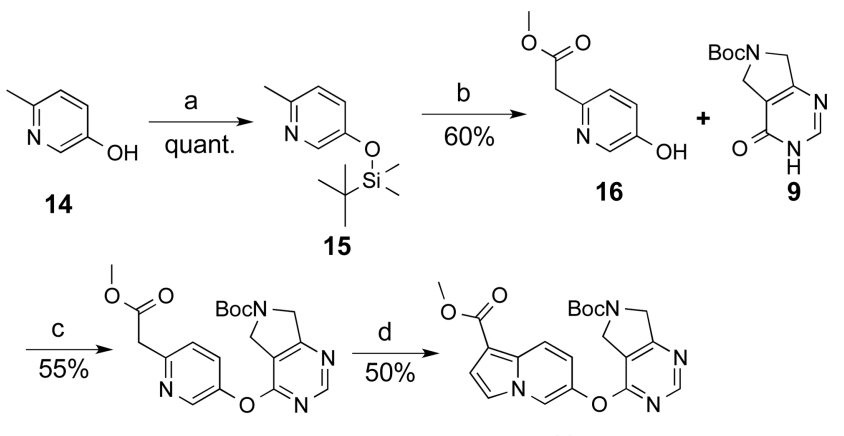

17

18

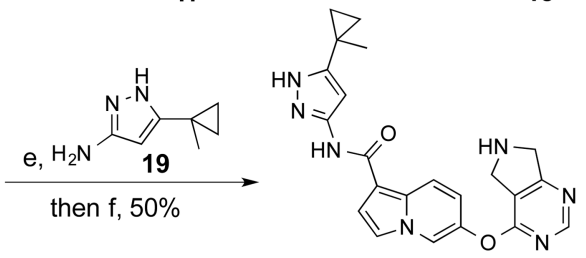

20

${ }^{a}$ Reagents and conditions: (a) $t \mathrm{BuMe}_{2} \mathrm{SiCl}$ ( 1 equiv), imidazole (2 equiv), DCM, $0{ }^{\circ} \mathrm{C}$ to rt, $2 \mathrm{~h}$; (b) LDA (4 equiv), dimethyl carbonate (4.1 equiv), $-78^{\circ} \mathrm{C}, 1 \mathrm{~h}$, then $1 \mathrm{~N} \mathrm{HCl}$ in ether ( 1 equiv), $\mathrm{MeOH}$, rt; (c) same as (b) in Scheme 2; (d) 2-chloroacetaldehyde (10 equiv), $\mathrm{NaHCO}_{3}$ (6 equiv), acetone, $70{ }^{\circ} \mathrm{C}$, overnight; (e) 19 (20 equiv), $\mathrm{Me}_{3} \mathrm{Al}$ (20 equiv), toluene, $100{ }^{\circ} \mathrm{C}, 8 \mathrm{~h}$; (f) DCM/TFA $(1: 1), 0{ }^{\circ} \mathrm{C}, 2$ h.

Scheme 4. Synthesis of Azaindoles 23 and 24 and Their Use in the Synthesis of VEGFR-2 Inhibitors 25 and 26,

Respectively $^{a}$<smiles>[R20][n+]1cccc2c1ccn2C(C)=O</smiles>

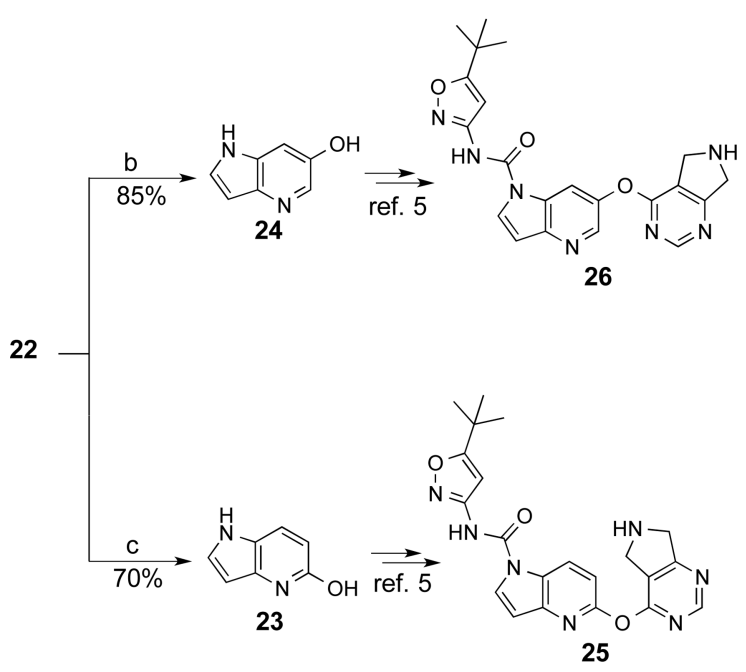

${ }^{a}$ Reagents and conditions: (a) $m$-CPBA (2 equiv), DCM, rt, overnight; (b) $\mathrm{Ac}_{2} \mathrm{O}$ (32 equiv), reflux, overnight, then $\mathrm{K}_{2} \mathrm{CO}_{3}$ (1.4 equiv), $\mathrm{MeOH}, 1 \mathrm{~h}$; (c) TFAA (5 equiv), DCM, $0{ }^{\circ} \mathrm{C}$ to rt, overnight, then $\mathrm{NH}_{4} \mathrm{OH}$. 
Table 1. "Core Replacement-" SAR: VEGFR-2 Potency, Solubility, and hERG

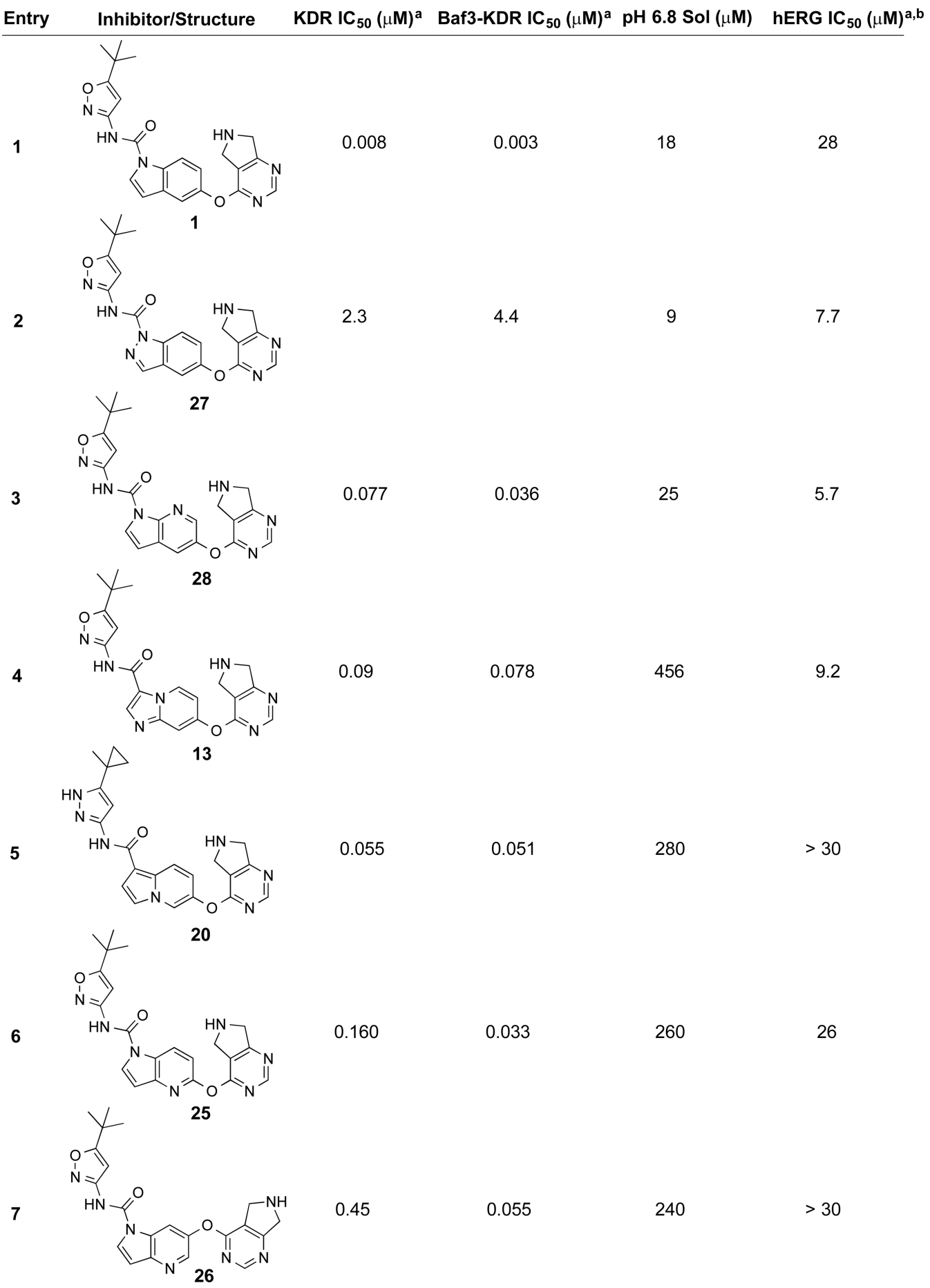

${ }^{a}$ Values are means of at least two experiments. ${ }^{b}$ Radioligand binding assay.

between hydroxy indole core $\mathbf{4}$ and chloropyrimidine $\mathbf{5}$ (Scheme 1) in addition to a urea formation reaction between the indole $\mathrm{NH}$ and an activated carbamate like 2. A conceptually similar overall synthetic plan was used for the synthesis of the new core structures presented below.

The imidazopyridine core, present in $\mathbf{1 3}$ (Scheme 2), was formed by simple condensation of aminopyridine $\mathbf{6}$ and chloroaldehyde 7 to give the desired core $8 .^{19}$ Hydroxyimidazo pyridine 8 was coupled with pyrimidinone 9 using modified peptide coupling conditions (PyBOP, DBU $)^{20}$ to give intermediate 10. After basic hydrolysis of the ethyl ester, the isoxazole amide was formed using standard conditions. The desired novel compound 13 was obtained after final Boc removal using a mixture of DCM and TFA.

The more unique core structure present in the VEGFR-2 inhibitor 20 (Scheme 3) was prepared starting from the hydroxy pyridine 14. Transient protection of the phenolic $\mathrm{OH}$ was used to facilitate the deprotonation and subsequent functionalization of the pyridyl 2-methyl group to afford ester 16. After PyBOP mediated coupling ${ }^{20}$ with pyrimidine 9, 
Table 2. 6-Hydroxyindole SAR and Comparison with 5-Hydroxyindole Analogues

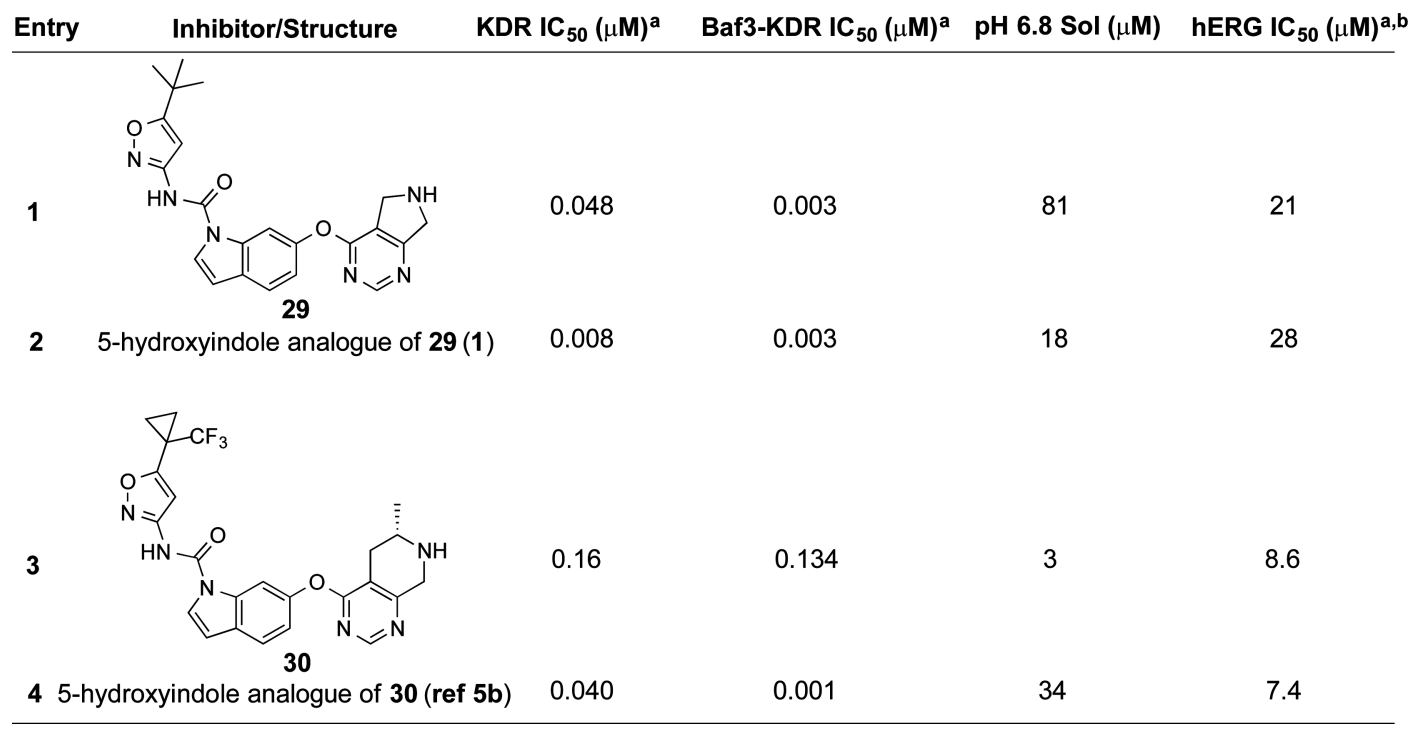

${ }^{a}$ Values are means of at least two experiments. ${ }^{b}$ Radioligand binding assay.

intermediate $\mathbf{1 7}$ was condensed with 2-chloroacetaldehyde in the presence of a weak base $\left(\mathrm{NaHCO}_{3}\right)$ to give pyrrolopyridine $18 .^{21}$ Trimethylaluminum mediated amidation with pyrazole 19 followed by deprotection afforded the wanted final compound 20. Unfortunately, amide formation did not proceed well when amino-isoxazole 12 was used in place of amino-pyrazole 19.

Azaindole core 23 (Scheme 4) was accessed using the wellestablished nucleophilic addition to pyridine $\mathrm{N}$-oxides. ${ }^{2-27}$ Interestingly, it was found that if pyridine $\mathrm{N}$-oxide 22 was heated to reflux in acetic anhydride, a meta addition of the acetate group was observed leading, after deprotection, to the initially undesired azaindole 24 . In order to access the desired azaindole 23 , treatment with TFAA at rt was found to be the optimal reaction condition. Transformation of 23 and 24 to their respective final compounds 25 and 26 was achieved following the same protocols as reported in ref 5 for compound 1.

Indazole $\mathbf{2 7}$ and azaindole $\mathbf{2 8}$ (in Table 1) were accessed starting, respectively, from commercially available $1 H$-indazole5-ol (CAS: 15579-15-4) and 1H-pyrrolo-[2,3-b]pyridin-5-ol (CAS: 98549-88-3) following the same protocols as reported in ref 5 for compound $\mathbf{1}$. Indoles $\mathbf{2 9}$ and $\mathbf{3 0}$ (in Table 2) were accessed starting from commercially available $1 H$-indol-6-ol (CAS: 2380-86-1) following the same protocols as reported in ref 5 for their 5-hydroxyindole analogues.

In vitro activity against the target VEGFR-2 receptor tyrosine kinase was assessed with two primary assays: a KDR receptor tyrosine kinase biochemical assay and a cellular assay with BaF3-Tel-KDR cells (an immortalized murine bone marrowderived pro-B-cell line) that are engineered to constitutively require VEGFR-2 kinase domain activity for survival and proliferation. The addition of an extra nitrogen to the 2position of the indole core of $\mathbf{1}$, to give indazole 27 (Entry 2, Table 1), resulted in a marked loss of potency ( $>1000$-fold). While aqueous solubility was similar for compound $\mathbf{1}$ and 27, counterintuitively (usually addition of polarity reduces affinity for hERG channel) the hERG affinity was enhanced. 7Azaindole 28 (Entry 3, Table 1) exhibited a slight drop in potency $(\sim 10$-fold $)$. The solubility profile was not altered, however in this case the affinity for the hERG channel was reduced (5.7 vs $28 \mu \mathrm{M}$ in $\mathbf{1}$ ). To our delight, the imidazopyridine (13, Entry 4, Table 1), which was a major departure from the usual indole-type core (note that the urea was now replaced with an amide), was found to be a potent VEGFR-2 inhibitor (90 and $78 \mathrm{nM}$, respectively, in the biochemical and cell assay). Additionally, 13 provided a large improvement in solubility ( 456 vs $18 \mu \mathrm{M}$ in 1). Again, it was disappointing to find that the polarity increase did not affect its ability to block the hERG channel $(9.2 \mu \mathrm{M})$. The novel pyrrolopyridine core containing compound 20 (Entry 5, Table 1) was also found to be a potent VEGFR-2 inhibitor (55 and 51 $\mathrm{nM}$, respectively, in the biochemical and cell assay). Although direct comparison of the changes in solubility and hERG in this compound are confounded by the different heterocycles in the amide region, 20 shows good solubility and minimal hERG affinity. It has been shown previously that amino pyrazoles are in general more efficient in improving both solubility and hERG profile of compounds of this type. ${ }^{5}$ 4-Azaindole 25 (Entry 6, Table 1) was pleasantly still potent against the target ( 160 and $33 \mathrm{nM}$, respectively, in the biochemical and cell assay) and also provided increased aqueous solubility (260 vs $18 \mu \mathrm{M}$ in 1). The 6-hydroxy-4-azaindole 26 (Entry 7, Table 1), serendipitously synthesized as a result of an unexpected reversed selectivity in the formation of its core structure (Scheme 4), was surprisingly still a potent VEGFR-2 inhibitor (450 and $55 \mathrm{nM}$, respectively, in the biochemical and cell assay). This finding highlighted the conformational flexibility of the connectivity between the core and hinge binding region. Solubility and hERG activity were similar to its 5-hydroxy analogue 25 .

Further investigation in this new series of 1-6 connected indole-pyrimidines showed that the nitrogen in the 4-position of the indole core in $\mathbf{2 6}$ was actually not needed for potency, and in fact, a simple and commercially available 6hydroxyindole core as in 29 (Entry 1, Table 2) was able to give rise to an exquisitely potent compound with comparable potency to the well optimized 5-hydroxyindole analogue. Further investigation into the potential binding mode showed that, while in the 5-hydroxyindole series the pyrimidine substitution allows for a very diverse $\mathrm{SAR}^{5}$ this is not the 
case for the 6-hydroxyindole series. Initial exploration seems to point to the importance of the 6,5-byclic pyrimidine present in 29. In fact, when a 6,6-substitued pyrimidine was coupled onto the 6-hydroxyindole core, compound 30 (Entry 3, Table 2), a $>100$-fold loss in potency against VEGFR-2 was observed compared to its 5-hydroxyindole analogue (Entry 4, Table 2).

The synthesis of a series of indole-core replacement within an optimized series of VEGFR-2 inhibitors and their impact on on-target potency, solubility and hERG affinity was reported herein. Generally, introducing additional nitrogens in the core structure was reasonably well tolerated, including cases where the connectivity of the core with the aminoheterocycle was changed from urea to amide. The most noticeable positive effect of such changes was observed on aqueous solubility, while the hERG affinity did not seem to be broadly reduced. The serendipitous synthesis of a 6-hydroxyindole analogue led to the uncovering of a novel connectivity for such series of compounds with potential vast implication on off-target profile, in vivo activity, and $\mathrm{pk}$.

\section{ASSOCIATED CONTENT}

\section{S Supporting Information}

The Supporting Information is available free of charge on the ACS Publications website at DOI: 10.1021/acsmedchemlett.6b00018.

Experimental details and ${ }^{1} \mathrm{H}$ NMR of compounds in Tables 1 and 2 (PDF)

\section{AUTHOR INFORMATION}

\section{Corresponding Authors}

*Phone: 1-857-201-2763. E-mail: nello@razetx.com.

*Phone: 1-617-871-7876. E-mail: james.powers@novartis.com.

\section{Present Address}

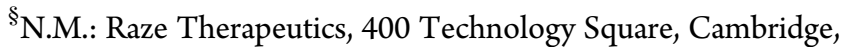
Massachusetts 02139, United States.

\section{Notes}

The authors declare no competing financial interest.

\section{ACKNOWLEDGMENTS}

The authors acknowledge the contribution of the Analytical Sciences group at the Novartis Institutes for Biomedical Research for support in generating the analytical details for the compounds described herein.

\section{ABBREVIATIONS}

VEGFR-2, vascular endothelial growth factor receptor 2; hERG, human Ether-à-go-go-related gene; PyBOP, benzotriazol-1-yloxytripyrrolidinophosphonium hexafluorophosphate; DBU, 1,8-diazabicyclo[5.4.0] undec-7-ene; SAR, structure-activity relationship; FCC, flash column chromatography; LCMS, liquid chromatography mass spectrometry

\section{REFERENCES}

(1) Brown, D. M.; Kaiser, P. K.; Michels, M.; Soubrane, G.; Heier, J. S.; Kim, R. Y.; Sy, J. P.; Schneider, S. Ranibizumab versus verteporfin for neovascular age-related macular degeneration. N. Engl. J. Med. 2006, 355, 1432-1444.

(2) Ferrara, N.; Davis-Smyth, T. The biology of vascular endothelial growth factor. Endocr. Rev. 1997, 18 (1), 4-25.

(3) Bates, D. O.; Curry, F. E. Vascular endothelial growth factor increases microvascular permeability via a $\mathrm{Ca} 2+-$ dependent pathway. Am. J. Physiol. 1997, 273, H687-694.
(4) Lopez, P. F.; Sippy, B. D.; Lambert, H. M.; Thach, A. B.; Hinton, D. R. Transdifferentiated retinal pigment epithelial cells are immunoreactive for vascular endothelial growth factor in surgically excised age-related macular degeneration-related choroidal neovascular membranes. Invest. Ophthalmol. Vis. Sci. 1996, 37 (5), 855-868.

(5) Meredith, E. L.; Mainolfi, N.; Poor, S.; Qiu, Y.; Miranda, K.; Powers, J.; Liu, D.; Ma, F.; Solovay, C.; Rao, C.; Johnson, L.; Ji, N.; Artman, G.; Hardegger, L.; Hanks, S.; Shen, S.; Woolfenden, A.; Fassbender, E.; Sivak, J.; Zhang, Y.; Long, D.; Cepeda, R.; Liu, F.; Hosagrahara, V.; Lee, W.; Tarsa, P.; Anderson, K.; Elliott, J.; Jaffee, B. Discovery of Oral VEGFR-2 Inhibitors with Prolonged Ocular Retention that are Efficacious in Models of Wet Age-Related Macular Degeneration. J. Med. Chem. 2015, 58 (23), 9273-9286.

(6) Shultz, M. D.; Cao, X.; Chen, C. H.; Cho, Y. S.; Davis, N. R.; Eckman, J.; Fan, J.; Fekete, A.; Firestone, B.; Flynn, J.; Green, J.; Growney, J. D.; Holmqvist, M.; Hsu, M.; Jansson, D.; Jiang, L.; Kwon, P.; Liu, G.; Lombardo, F.; Lu, Q.; Majumdar, D.; Meta, C.; Perez, L.; Pu, M.; Ramsey, T.; Remiszewski, S.; Skolnik, S.; Traebert, M.; Urban, L.; Uttamsingh, L.; Wang, P.; Whitebread, S.; Whitehead, L.; YanNeale, Y.; Yao, Y.-M.; Zhou, L.; Atadja, P. Optimization of the in Vitro Cardiac Safety of Hydroxamate-Based Histone Deacetylase Inhibitors. J. Med. Chem. 2011, 54, 4752-4772.

(7) Bell, I. M.; Gallicchio, S. N.; Abrams, M.; Beshore, D. C.; Buser, C. A.; Culberson, J. C.; Davide, J.; Ellis-Hutchings, M.; Fernandes, C.; Gibbs, J. B.; Graham, S. L.; Hartman, G. D.; Heimbrook, D. C.; Homnick, C. F.; Huff, J. R.; Kassahun, K.; Koblan, K. S.; Kohl, N. E.; Lobell, R. B.; Lynch, J. J., Jr.; Miller, P. A.; Omer, C. A.; Rodrigues, A. D.; Walsh, E. S.; Williams, T. M. Design and Biological Activity of $(S)$ 4-(5-\{[1-(3-Chlorobenzyl)-2-oxopyrrolidin-3-ylamino $]$ methyl $\}$ imidazol-1-ylmethyl)benzonitrile, a 3-Aminopyrrolidinone Farnesyltransferase Inhibitor with Excellent Cell Potency. J. Med. Chem. 2001, 44, 2933-2949.

(8) Siu, T.; Li, Y.; Nagasawa, J.; Liang, J.; Tehrani, L.; Chua, P.; Jones, R. E.; Defeo-Jones, D.; Barnett, S. F.; Robinson, R. G. The design and synthesis of potent and cell-active allosteric dual Akt 1 and 2 inhibitors devoid of hERG activity. Bioorg. Med. Chem. Lett. 2008, 18, 41914194.

(9) For an excellent review of hERG Optimization in Medicinal Chemistry, see: (e) Jamieson, C.; Moir, E. M.; Rankovic, Z.; Wishart, G. Medicinal chemistry of hERG optimizations: Highlights and hangups. J. Med. Chem. 2006, 49, 5029-5046.

(10) Tamargo, J. Drug-induced torsade de pointes: from molecularbiology to bedside. Jpn. J. Pharmacol. 2000, 83, 1-19.

(11) Witchel, H. J.; Hancox, J. C. Familial and acquired longqt syndrome and the cardiac rapid delayed rectifier potassium current. Clin. Exp. Pharmacol. Physiol. 2000, 27, 753-766.

(12) Recanatini, M.; Poluzzi, E.; Masetti, M.; Cavalli, A.; De, P. F. QT prolongation through hERG $\mathrm{K}(+)$ channel blockade: current knowledge and strategies for the early prediction during drug development. Med. Res. Rev. 2005, 25, 133-166.

(13) Lagrutta, A. A.; Trepakova, E. S.; Salata, J. J. The hERG channel and risk of drug-acquired cardiac arrhythmia: an overview. Curr. Top. Med. Chem. 2008, 8, 1102-1112.

(14) Redfern, W. S.; Carlsson, L.; Davis, A. S.; Lynch, W. G.; MacKenzie, I.; Palethorpe, S.; Siegl, P. K.; Strang, I.; Sullivan, A. T.; Wallis, R.; Camm, A. J.; Hammond, T. G. Relationships between preclinical cardiac electrophysiology, clinical QT interval prolongation and torsade de pointes for a broad range of drugs: evidence for a provisional safety margin in drug development. Cardiovasc. Res. 2003, $58,32-45$.

(15) Kerr, J. S.; Galloway, S.; Lagrutta, A.; Armstrong, M.; Miller, T.; Richon, V. M.; Andrews, P. A. Nonclinical safety assessment of the histone deacetylase inhibitor vorinostat. Int. J. Toxicol. 2010, 29, 3-19. Munster, P. N.; Rubin, E. H.; Van, B. S.; Friedman, E.; Patterson, J. K.; Van, D. K.; Li, X.; Comisar, W.; Chodakewitz, J. A.; Wagner, J. A.; Iwamoto, M. A single supratherapeutic dose of vorinostat does not prolong the QTc interval in patients with advanced cancer. Clin. Cancer Res. 2009, 15, 7077-7084. 
(16) Borchard, U.; Hafner, D. Ion channels and arrhythmias. Z. Kardiol. 2000, 89, 6-12.

(17) Ritchie, T. J.; Macdonald, S. J. F.; Peace, S.; Pickett, S. D.; Luscombe, C. N. The developability of heteroaromatic and heteroaliphatic rings - do some have a better pedigree as potential drug molecules than others? MedChem Comm 2012, 3 (9), 1062-1069.

(18) Meanwell, N. A. Improving drug candidates by design: a focus on physicochemical properties as a means of improving compound disposition and safety. Chem. Res. Toxicol. 2011, 24, 1420-1456.

(19) Ikemoto, T.; Kawamoto, T.; Wada, H.; Ishida, T.; Ito, T.; Isogami, Y.; Miyano, Y.; Mizuno, Y.; Tomimatsu, K.; Hamamura, K.; Takatani, M.; Wakimasu, M. Large-scale Synthesis of new Cyclazines, 5-thia-1,8b-diazaacenaphthlene-3-carboxylic acid derivatives having the peripheral 12- $\pi$ electron ring system. Tetrahedron 2002, 58, 489-493.

(20) Wan, Z.-K.; Wacharasindhu, S.; Levins, C. G.; Lin, M.; Tabei, K.; Mansour, T. S. The Scope and Mechanism of PhosphoniumMediated SNAr Reactions in Heterocyclic Amides and Ureas. J. Org. Chem. 2007, 72, 10194-10210.

(21) Modified from Bragg, D. R.; Wibberley, D. G. Preparation of Indolixines from Ethyl 2 - Pyridylacetate. J. Chem. Soc. 1962, 26272629.

(22) Keith, J. M. One-step Conversion of Azine N-oxides to Alpha1,2,4-triazolo-, 1,2,3-triazolo, imidazolo-, and Pyrazoloheteroarenes. J. Org. Chem. 2010, 75, 2722-2725.

(23) Storz, T.; Bartberger, M. D.; Sukits, S.; Wilde, C.; Soukup, T. The First Practical and Efficient One-Pot Synthesis of 6-Substituted 7Azaindoles via a Reissert-Henze Reaction. Synthesis 2008, 2008, 201-214.

(24) Yin, J.; Xiang, B.; Huffman, M. A.; Raab, C. E.; Davies, I. W. A General and Efficient 2-Amination of Pyridines and Quinolines. J. Org. Chem. 2007, 72, 4554-4557.

(25) Solekhova, M. A.; Kurbatov, Y. V. Reductive Amination of Quinoline N-Oxide with Aminopyridines and Their N-Tozyl Derivatives. Russ. J. Org. Chem. 2002, 38, 1192-1194.

(26) Hayashida, M.; Honda, H.; Hamana, M. Deoxygenative 2Alkoxylation of Quinoline 1-Oxide. Heterocycles 1990, 31, 1325-31.

(27) LaMontagne, M. P.; Blumbergs, P.; Smith, D. C. Synthesis of 2substituted analogues of 8-[(4-amino-1-methylbutyl)amino]-6-methoxy-4-methyl-5-[3- (trifluoromethyl)phenoxy] quinoline as candidate antimalarials. J. Med. Chem. 1989, 32, 1728-32. 